\title{
Rapid in situ Formation and Densification of Titanium Boride (TiB) Nano-ceramic via Transient Liquid Phase in Electric Field Activated Sintering
}

\author{
J. Du, A.P. Sanders, V. Jindal, K.S. Ravi Chandran*
}

Department of Metallurgical Engineering, University of Utah, Salt Lake City, UT 84112, USA

Rapid in situ synthesis of bulk nanostructured titanium boride (TiB) ceramic, at the lowest possible processing temperature, is demonstrated. Using electric-field-activated-sintering (EFAS), nanoscale TiB whiskers were formed and densified uniformly throughout the volume, from a mixture of micron-sized $\mathrm{Ti}, \mathrm{TiB}_{2}$ and $\mathrm{FeMo}$ powders, at $1100{ }^{\circ} \mathrm{C}$ in 30 minutes and at a relatively low pressure. Microstructure and X-ray diffraction (XRD) analysis, revealing the formation of $\mathrm{TiB}$ whiskers in this rapid processing condition, are presented. The formation of a transitional quaternary liquid phase, facilitated by localized joule heating at particle contacts, are hypothesized as contributors to rapid and low-temperature synthesis.

Key words: Titanium Boride; Electric field activated reactive sintering; Low temperature; Densification.

\section{* Corresponding author E-mail address: Ravi.Chandran@utah.edu}

The prospect of achieving a dense, refined microstructure in ceramics during sintering, at the lowest possible temperature, is not only scientifically intriguing but also practically very important in the context of reducing time and the cost of manufacturing. In this context, the electric-field-activated-sintering (EFAS) process has emerged as a promising approach, for ceramics [1,2], cermets [3,4], and metal matrix composites [5,6]. With EFAS, there is potential to reduce the sintering temperature and time because of the generation of high rates of heat by the passage of an electrical current through the conductive powders, which can accelerate local heating and diffusion, reaction, and sintering. A combination of these processes, which depends on the ceramic, can lead to rapid densification with a very fine grain size and a uniform microstructure. An open question, however, is whether the relevant chemical reaction, especially in the context of reaction sintering of ceramics, will be completed, and the ceramic will be densified, in the relatively shorter processing time.

Titanium boride (TiB) is a new, hard, nano-ceramic material that was previously synthesized in our group [7, 8, 9] by hot-pressing of constituent powders. The major attractive feature of this boride ceramic is its dense, highly compact, and three-dimensional network of nanostructured TiB whiskers, which gives the ceramic the bulk form. This ceramic has been shown to have a very attractive set of mechanical properties: relatively high values of hardness $\left(\sim 1600-1800 \mathrm{~kg} / \mathrm{mm}^{2}\right)$ [10], Young's modulus ( 427 GPa) [11], flexure strength $(\sim 850 \mathrm{MPa})$ [10], fracture toughness $(5.2 \mathrm{MPa} \sqrt{\mathrm{m}})$, and, excellent wear 
resistance against $\mathrm{Si}_{3} \mathrm{~N}_{4}$ [12]. These properties are quite compelling and mark the excellent potential for engineering applications. Our previous work, however, was based on hot-pressed samples (75 x $75 \times 12.7 \mathrm{~mm}$ ) of bulk nanostructured TiB. However, for complete reactive formation and densification of $\mathrm{TiB}$ in hot pressing, a temperature of at least $1350{ }^{\circ} \mathrm{C}$ and a period of 2 hours, at a pressure of 15-20 MPa, were required.

In this report, we demonstrate the first synthesis of bulk nanostructured $\mathrm{TiB}$, at the lowest possible temperature $\left(1100{ }^{\circ} \mathrm{C}\right)$ and in a relatively short time ( $\sim 30$ minutes.), which resulted in uniform reaction and formation of $\mathrm{TiB}$ whiskers and produced a completely dense ceramic. The mechanism of formation of needle-like TiB during reaction sintering was actually first reported in our past work [13]. A later work [14] reported needle-like $\mathrm{TiB}_{2}$ phase formed in spark plasma sintering (SPS) of titanium and boron powders. However, the sintered microstructure was highly porous at sintering temperatures $<1500{ }^{\circ} \mathrm{C}$. A sintering temperature of at least $1600{ }^{\circ} \mathrm{C}$ in EFAS was required to produce a nearly $100 \%$ dense microstructure. This probably indicates that full densification of the borides cannot be attained at low temperatures without sintering aids. We have investigated the formation of $\mathrm{TiB}$ whiskers and the densification of the microstructure, during the reaction sintering of micron-sized $\mathrm{Ti}, \mathrm{TiB}_{2}$ and $\mathrm{FeMo}$ powders, and with the assistance of a transient liquid phase, at temperatures ranging from $800{ }^{\circ} \mathrm{C}$ to $1350{ }^{\circ} \mathrm{C}$. The objective is to find the lowest sintering temperature at which full $\mathrm{TiB}$ whisker formation and full densification can be achieved. The use of FeMo powder is intended to accelerate the reaction through the formation of a liquid phase. The processing was done by EFAS, taking advantage of the electrically conducting nature of the reactants. Density, microstructure, phase evolution, and hardness of EFAS-processed samples were evaluated.

The present work employed a starting powder mixture consisting of Ti powder $(99.7 \%$ pure; average particle size of $45 \mu \mathrm{m}$; Atlantic Equipment Engineers, NJ), $\mathrm{TiB}_{2}$ powder $(99.7 \%$ pure; average particle size of $10 \mu \mathrm{m}$; Atlantic Equipment Engineers, NJ), and Fe-Mo alloy powder (59.8 wt\% Mo; average particle size $10 \mu \mathrm{m}$; F.W. Winter Inc.\& Co., Camden, NJ). The mixture was blended for 24 hours on a jar mill. The composition of the mixture (in wt. $\%$ ) is $47.4 \% \mathrm{Ti}, 48 \% \mathrm{TiB}_{2}, 4.6 \% \mathrm{Fe}-\mathrm{Mo}$. This is the same as that used earlier for processing nearly $100 \% \mathrm{TiB}$ ceramic by hot pressing [7]. A 10 ton spark plasma sintering system (Model 10-4, Thermal Technologies, Santa Rosa, CA) was used to perform the EFAS processing at reaction temperatures in the range of $800-1350{ }^{\circ} \mathrm{C}$. To evaluate the effect of temperature on the reactive formation and densification of $\mathrm{TiB}$, the pressure (10 $\mathrm{MPa})$, the heating rate $\left(50{ }^{\circ} \mathrm{C} / \mathrm{min}\right)$, the holding time at the process temperature (30 minutes $)$, and the cooling rate $\left(22.5^{\circ} \mathrm{C} / \mathrm{min}\right.$ to $\left.800{ }^{\circ} \mathrm{C}\right)$ were kept constant.

Samples for microstructure observations were prepared following the standard procedure for ceramics. Density was measured by Archimedes's method. A Vickers hardness tester (LECO, M-400) was employed to measure the micro-hardness at $1 \mathrm{~kg}$ load. At least 16 random measurements were made to provide a statistical and spatial sampling of the 
uniformity of TiB phase in the microstructure. An X-ray diffractometer (Rigaku, Miniflex 600 ), with a scan step of 0.5 degrees per minute was used to obtain the diffraction patterns. The samples were etched with Kroll's reagent, and the microstructures were examined in a SEM (FEI Quanta 200, USA). Energy-dispersive X-ray (EDAX) mapping was performed to investigate the spatial distribution of $\mathrm{Fe}$ and $\mathrm{Mo}$ in the microstructure.

Fig. 1 shows that the density and micro-hardness of $\mathrm{TiB}$ nano-ceramic increase with the sintering temperature and reach the saturation levels at $1100{ }^{\circ} \mathrm{C}$. The saturation density is quite close to the theoretical density of the $\mathrm{TiB}$, which, for the present composition, is estimated to be $\sim 4.6 \mathrm{~g} / \mathrm{cm}^{3}$. The saturation micro-hardness $\left(\sim 1800 \mathrm{~kg} / \mathrm{mm}^{2}\right)$ is at the higher end of the values previously reported for the hot-pressed condition $\left(1600-1800 \mathrm{~kg} / \mathrm{mm}^{2}\right)$. In the present EFAS processing, the relevant in situ reaction is given by

$$
\mathrm{Ti}+\mathrm{TiB}_{2}+\mathrm{Fe}-\mathrm{Mo}=2(\mathrm{Ti}, \mathrm{Fe}, \mathrm{Mo}) \mathrm{B}+\beta-\mathrm{Ti}
$$

where the left side shows the composition of powders participating in the reaction. The right side is the composition of the products of reaction, which includes the ternary titanium boride that is substitutionally alloyed with Fe and Mo and a small amount (< 5 vol.\%) of retained metallic beta-titanium ( $\beta$-Ti) phase containing Fe and Mo in solid solution. This is the targeted result, with the large fraction ( $>95 \mathrm{vol} . \%$ ) of boride phase providing hardness and strength and the small amount of the beta phase providing some toughness to the nano-ceramic.

Fig. 2(a) shows the variation of input power, with time, for the different sintering conditions of EFAS processing. There is a general similarity of the power-input curves, and this is largely due to the constant heating rate, cooling rate and holding time. In all cases, when the set point temperatures were reached, the input power dropped and, after a small fluctuation, remained constant around the steady-state power. The variation of ram displacement during sintering was also recorded to correlate the densification behavior with the input power and the temperature variations during the process cycle. Fig. 2(b) shows the ram displacement data. The ram displacements were rapid in the initial stage of processing, for the sintering temperatures in the range of $1100-1350{ }^{\circ} \mathrm{C}$, indicating the rapid densification of the material. For these samples, the actual densification seems to begin around $500{ }^{\circ} \mathrm{C}$ (about 500 seconds from the beginning of the process) and is completed in about 1500 seconds from the start. Most of the rapid densification, however, seems to occur within about 100 seconds after the temperature had reached $1060{ }^{\circ} \mathrm{C}$. This is evident from the large ram displacement (>5 mm) during this period. In contrast, the total ram displacements for samples sintered at $800-900{ }^{\circ} \mathrm{C}$ were much lower. The ram displacement is gradual during sintering at $1000{ }^{\circ} \mathrm{C}$ and this probably indicates the slower pace of reaction and densification relative to what happened at temperatures above $1100^{\circ} \mathrm{C}$.

The rapid ram displacement at the temperatures of $1100{ }^{\circ} \mathrm{C}$ and above, is therefore quite distinct, and, characterizes the rapid reaction and densification of the $\mathrm{TiB}$ at these 
temperatures. Thermodynamically, this can be explained by the formation of a quaternary eutectic liquid phase that seems to have assisted in the reactive formation of TiB phase and the consequent densification of the bulk ceramic. In the Ti-Fe phase diagram [15], a eutectic reaction $(\mathrm{Ti}(\mathrm{L})+\mathrm{TiFe})$ occurs at $1085 \pm 5{ }^{\circ} \mathrm{C}$, which is very close to the temperature at which the large change in ram displacement occurred in the present experiments. It is also known that the sintering behavior of Ti powders is enhanced $[16,17]$ by the addition of $\mathrm{Fe}$ powder, quite possibly by the same liquid phase. The presence of Mo and B may change slightly the eutectic liquid phase formation temperature, but the present experimental evidence $\left(1060^{\circ} \mathrm{C}\right)$ actually points to the possible formation of this liquid at a temperature lower than that of the Ti-Fe eutectic. Further research, using CALPAHD approach, is in progress to determine the composition and the temperature of formation of the quaternary eutectic liquid within the Ti-B-Fe-Mo system.

The X-ray diffraction patterns of the present samples, given in Figure 3(a), show that the residual $\mathrm{Ti}$ and $\mathrm{TiB}_{2}$ phase peaks are present only in the samples sintered at $800-1000{ }^{\circ} \mathrm{C}$. They are completely eliminated in samples sintered at $1100{ }^{\circ} \mathrm{C}$ and above. Almost all of the $\mathrm{X}$-ray peaks present in the samples processed at temperatures from 1100 to $1350{ }^{\circ} \mathrm{C}$ belong to the $\mathrm{TiB}$ phase. This confirms that the $\mathrm{TiB}$ formation is complete at $1100{ }^{\circ} \mathrm{C}$. In conjunction with the density data in Figure 1, one can thus conclude that the complete reaction and densification is complete at $1100{ }^{\circ} \mathrm{C}$. The formation of $\mathrm{TiB}$ occurs by the growth of $\mathrm{TiB}$ whiskers from $\mathrm{TiB}_{2}$ particles, which is enabled by the diffusion of $\mathrm{B}$ along the [010] direction of TiB phase, as explained in our previous works [7,13]. A high resolution XRD analysis indicated that a very high proportion of $\mathrm{TiB}(>95 \mathrm{vol} \%$ ) has been formed in the ceramic. A small amount of residual $\beta$-Ti is present in the microstructure (indicated by arrows in Figure 4), as evidenced by the $[110]_{\beta \text {-Ti }}$ peak in the diffratogram. Thus, the samples sintered at and above $1100{ }^{\circ} \mathrm{C}$ have only $\mathrm{TiB}$ and $\beta$-Ti phases after sintering and these are the equilibrium phases that are supposed to be present because $\mathrm{Fe}$ and Mo are beta-stabilizers in titanium. A closer analysis of the diffraction peak positions indicated that the 2-theta positions of $[110]_{\beta-\mathrm{Ti}},[210]_{\mathrm{TiB}}$, and $[102]_{\mathrm{TiB}}$ peaks actually have shifted to the right, which indicates a decrease in the interplanar spacings of both $\beta$-Ti and $\mathrm{TiB}$ phases. This indicates the changing levels of alloying of TiB and $\beta$-Ti phase with the process temperature and is consistent with our previous work [7] where the peak shifts in the hot-pressed samples were correlated to the changes in the amounts of Fe and Mo in the $\beta$-Ti phase. It is also intriguing to note that the beginning of the decrease in the interplanar spacing of $\beta$-Ti phase occurs at $1100{ }^{\circ} \mathrm{C}$, which is the minimum temperature for full $\mathrm{TiB}$ conversion and densification.

Figure 4(a-f) presents the SEM micrographs of the samples sintered at 1000, 1100 and $1350{ }^{\circ} \mathrm{C}$. The completion of $\mathrm{TiB}$ formation and full densification at $1100{ }^{\circ} \mathrm{C}$ (and above) is evident from a comparison of Fig. 4(a,b) with Fig. 4(c,d). The microstructures of the sample sintered at $1100{ }^{\circ} \mathrm{C}$ (Fig. 4c,d) and that sintered at $1350{ }^{\circ} \mathrm{C}$ (Fig. 4(e,f)) are very similar, supporting the observation that all reaction sintering and densification is complete at 
$1100{ }^{\circ} \mathrm{C}$. As indicated earlier, this can be explained by the formation of a quaternary eutectic liquid phase at a temperature of about $1060{ }^{\circ} \mathrm{C}$, which is below the eutectic temperature $\left(\sim 1085^{\circ} \mathrm{C}\right)$ of the $\beta-\mathrm{Ti}+\mathrm{TiFe}$ section in the Ti-Fe system. It is possible that EFAS creates locally higher temperature at the particle contacts where joule heating is maximal, and this characteristic of EFAS facilitates the formation of a small amount of liquid phase below the predicted eutectic temperature. Elemental X-ray mapping (Fig. 4g-i) revealed that the light patches present in Fig. $4 \mathrm{~g}$ are actually regions within the $\mathrm{TiB}$ phase that are enriched with Fe. The TiB phase is at least $95 \%$ by volume; hence, these regions seem to approximately correspond to the former sites of the eutectic liquid that was present in the early stages of processing. These regions were partly converted into $\mathrm{TiB}$, due to the later growth of $\mathrm{TiB}$ whiskers into these regions during the final stage of reaction, as can be inferred from Fig. $4 \mathrm{~d}$ and 4e. On the other hand, Mo is found to be distributed uniformly thought the TiB matrix (Fig. 4i), which indicates the rapid diffusion of Mo during the formation of TiB and its incorporation in $\mathrm{TiB}$ in the present experiments. A large fraction of Fe and/or Mo atoms will be substitutionally incorporated into the orthorhombic TiB phase because the monoborides, $\mathrm{FeB}$ and $\mathrm{MoB}$ also have orthorhombic crystal structure and hence are isostructural with the TiB compound. The Vickers hardness measurements are at a size scale that is larger than the scale of variation of Fe. Hence, the relatively high level of reproducibility of hardness values is understandable.

In summary, it has been shown here that rapid formation of $\mathrm{TiB}$ whiskers and densification of $\mathrm{TiB}$ ceramic with a nanoscale microstructure can be achieved at the lowest possible temperature of $1100{ }^{\circ} \mathrm{C}$ in 30 minutes and with a pressure of $10 \mathrm{MPa}$. The full densification at a relatively low processing temperature $\left(1100^{\circ} \mathrm{C}\right)$ is caused by the likely formation of a quaternary eutectic liquid phase, which triggered the fast reaction, conversion, and densification of TiB. The samples also achieved full density, and the maximum attainable microhardness, uniformly in the boride. During the formation of TiB, Mo was found to be uniformly alloyed, but Fe was segregated in the regions that were the former sites of the eutectic liquid phase at the processing temperature. Nevertheless, a uniform microstructure consisting largely of a ternary titanium boride, $\mathrm{Ti}(\mathrm{Fe}, \mathrm{Mo}) \mathrm{B}$ and a ductile residual beta-Ti phase has formed in the ceramic.

\section{Acknowledgement}

The research was supported by the National Science Foundation, the program on Designing Materials to Revolutionize our Engineering Future (DMREF), through the grant CMMI-1435758. 


\section{References}

[1] Z. Munir, U. Tamburini. J. Mater. Sci. 41 (2006) 763.

[2] T. Nishimura, M. Mitomo, H. Hirotsuru, M. Kawahara. J. Mater. Sci. Lett. 15(1995)1046.

[3] P. Angerer, L. Yu, K. Khor, G. Korb, I. Zalite. J. Eur. Ceram. Soc.11 (2005): 1919-1927.

[4] N.S. Karthiselva, B.S. Murty, S.R. Bakshi, Scripta Mater. 110 (2016) 78.

[5] H. Kwon, M. Estili, K. Takagi, T. Miyazaki, A. Kawasaki. Carbon. 47 (2009) 570.

[6] F. Monteverde, C. Melandri, S. Guicciardi. Mater. Chem. Phys. 100 (2006) 513.

[7] S. Madtha, K.S. Ravi Chandran, J. Am. Ceram. Soc. 95 (2012) 117.

[8] K. S. Ravi Chandran. (2009). U.S. Patent No. 7,501,081. Washington, DC: U.S. Patent and Trademark Office.

[9] K. S. Ravi Chandran. (2008). U.S. Patent No. 7,459,105. Washington, DC: U.S. Patent and Trademark Office.

[10] S. Madtha, C. Lee, K. S. Ravi Chandran, J. Am. Ceram. Soc. 91(2008) 1319.

[11] K. Panda, K. S. Ravi Chandran, Acta Mater. 54(2006) 1641.

[12] C. Lee, M.S. Thesis, Department of Metallurgical Engineering, Univeristy of Utah, 2007.

[13] Sahay, S. S., K. S. Ravi chandran, R. Atri, B. Chen, and J. Rubin. J. Mater. 11 (1999) 4214.

[14] J. Schmidt, M. Boehling, U. Burkhardt, and Y. Grin. Sci. Tech. Adv. Mater. 5 (2007) 376.

[15] H. Okamoto, Journal of Phase Equilibria 17 (1996) 369

[16] W. Wei, Y. Liu, K. Zhou, B. Huang, Powder Metallurgy 46 (2003) 246

[17] R. M. German, P. Suri , S. J. Park, Journal of Materials Science 44 (2009) 1 


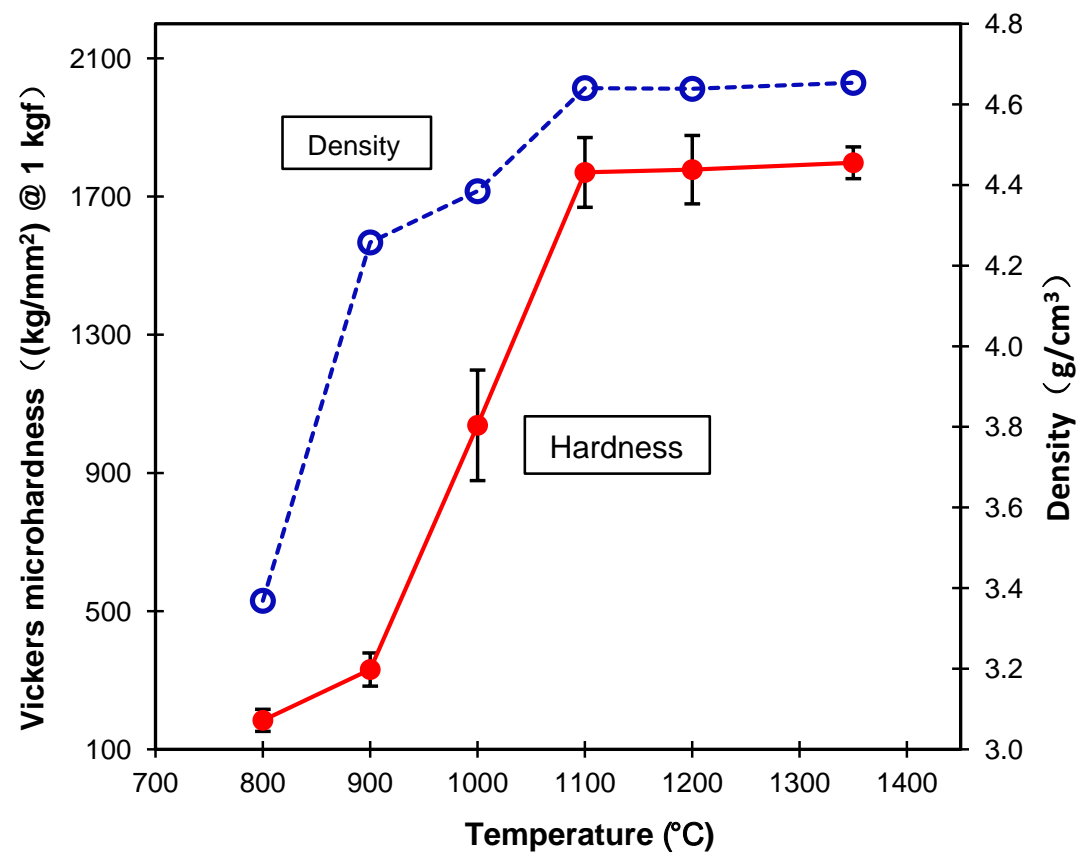

Fig. 1. The variation of density and Vickers micro-hardness with the process temperature 

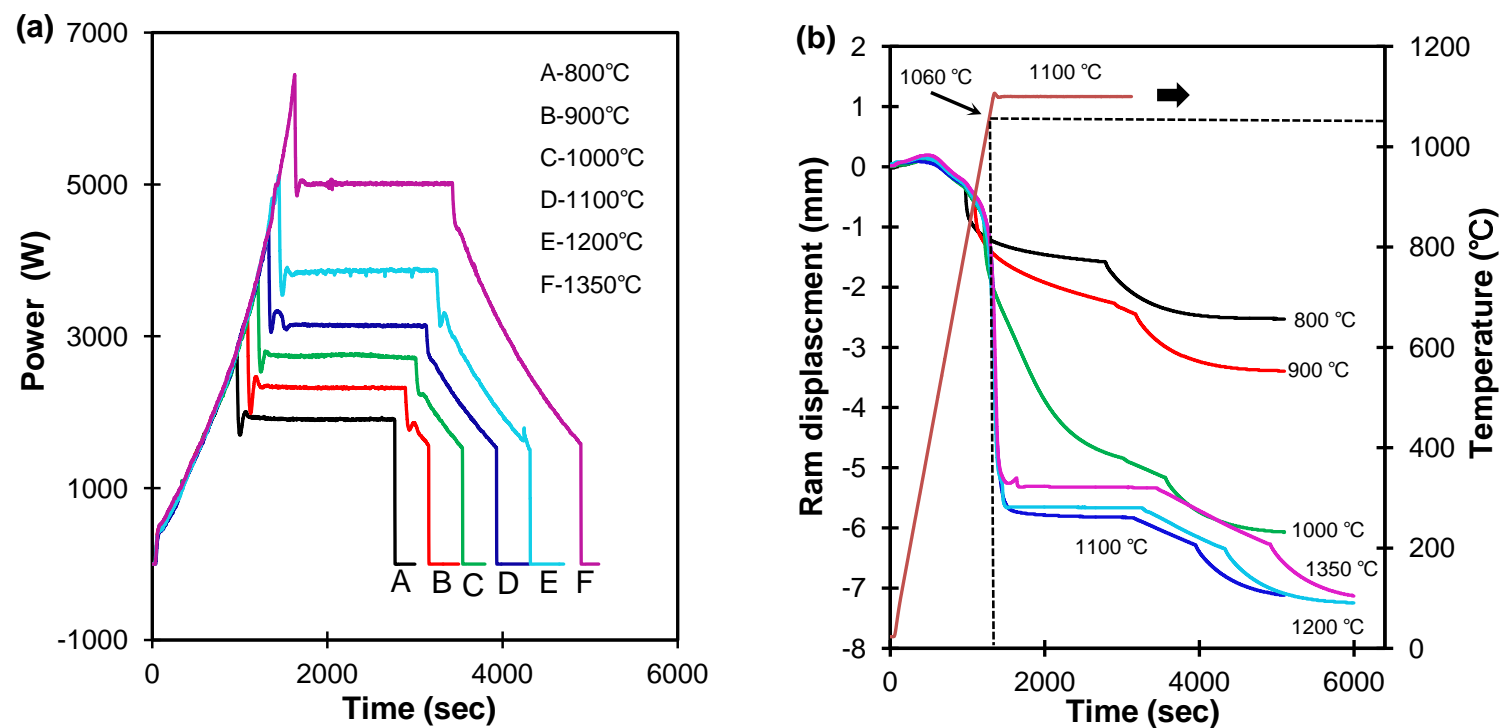

Figure 2. (a) Power input versus time curves of EFAS samples processed at different temperatures. (b) Ram displacement during EFAS processing and the temperature-time profile for the processing at $1100{ }^{\circ} \mathrm{C}$. 

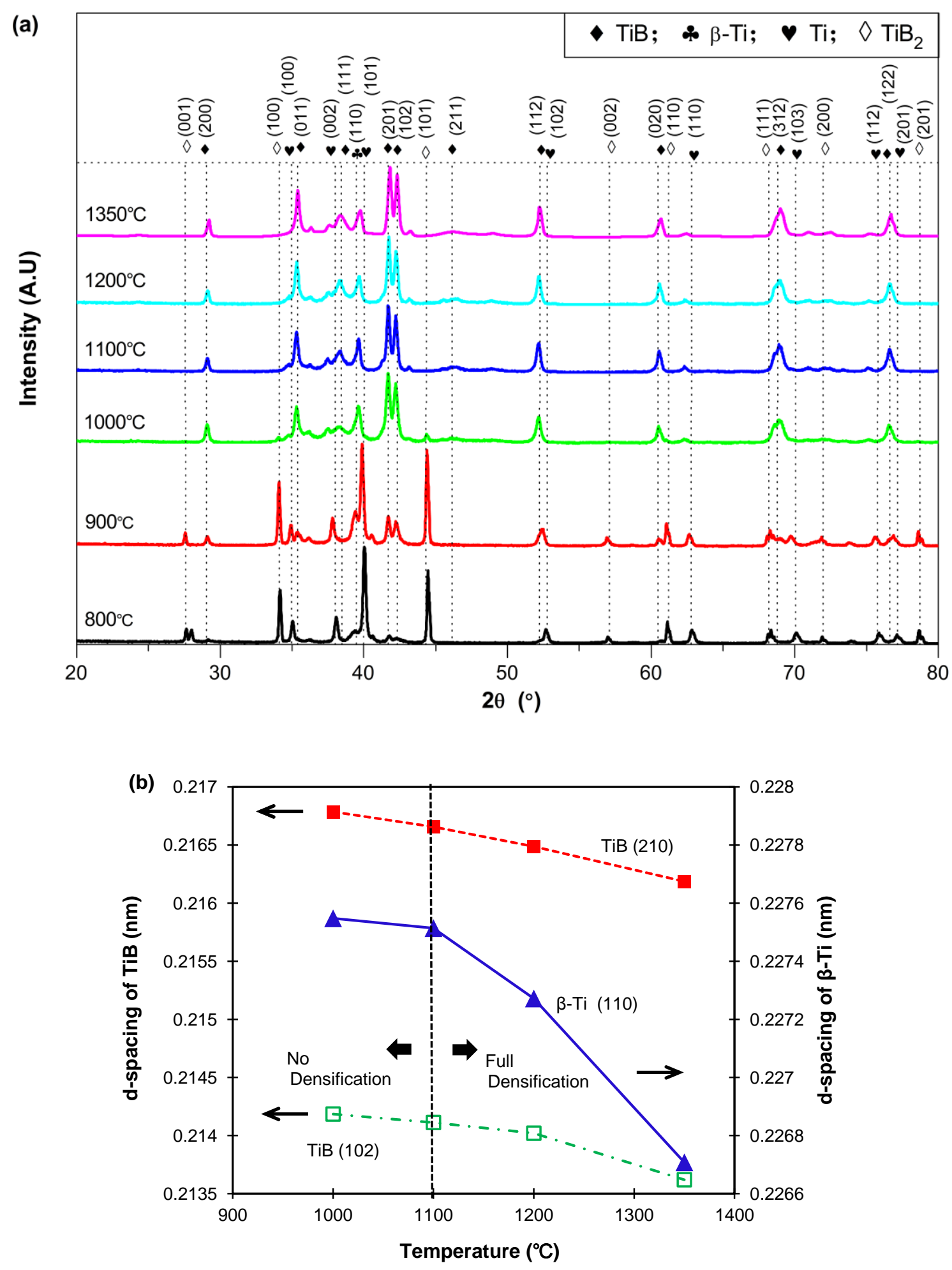

Figure 3. (a) X-ray diffraction patterns of EFAS processed samples. (b) The effect of processing temperature on the inter-planar spacing of $(110)_{\beta-\mathrm{Ti}}$ plane and $(210)_{\mathrm{TiB}},(102)_{\mathrm{TiB}}$ planes. 

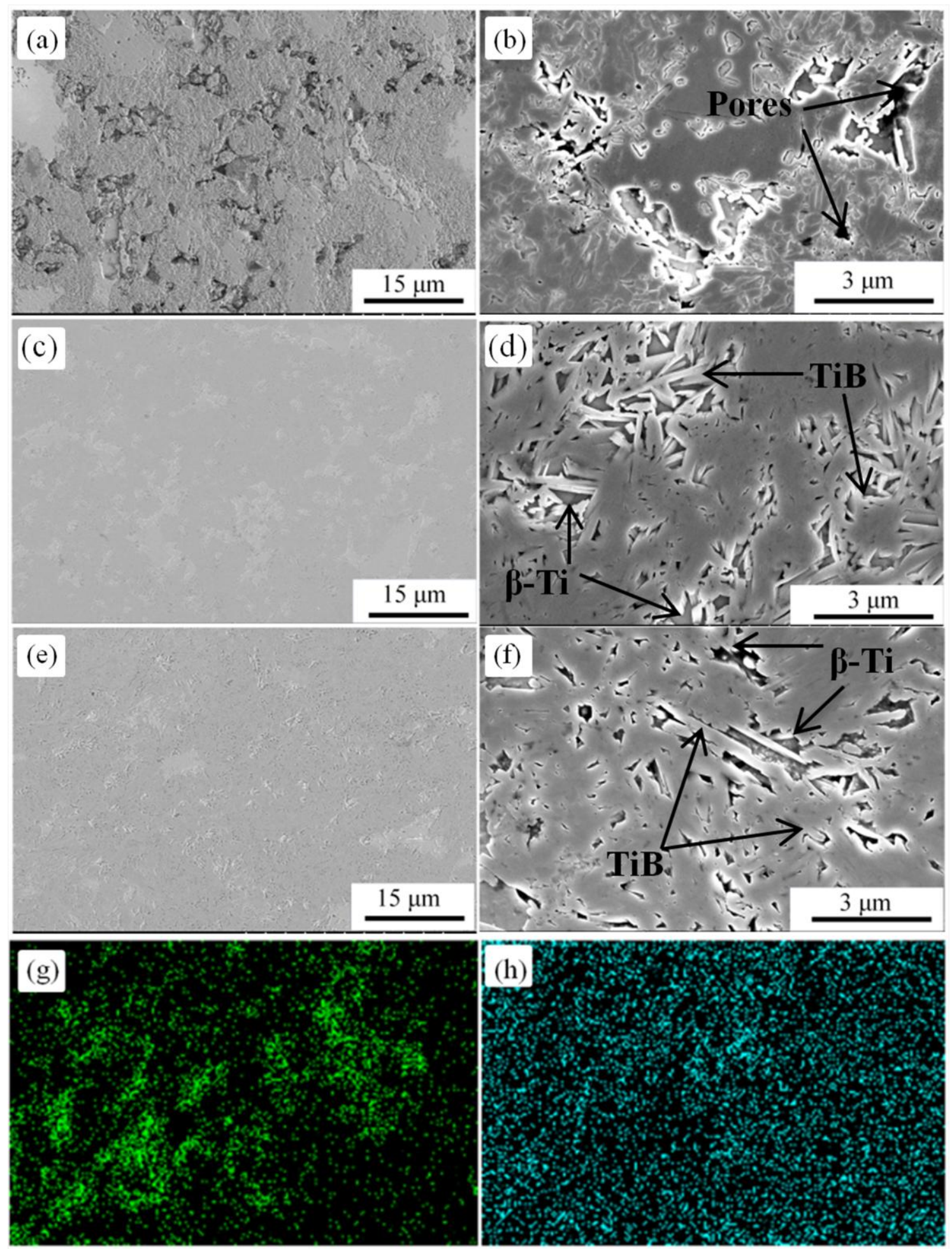

$25 \mu \mathrm{m}$

$\mathrm{Fe} \mathrm{K} \alpha 1$

$25 \mu \mathrm{m}$

Mo L $\alpha 1$

Figure 4. (a), (c), and (e) are low magnification SEM images of samples sintered at 1000, 1100 , and $1350{ }^{\circ} \mathrm{C}$, respectively. (b), (d), and (f) are the corresponding high magnification SEM images. The elemental mapping of the distribution of $\mathrm{Fe}$ and $\mathrm{Mo}$, for the sample sintered at $1100{ }^{\circ} \mathrm{C}$, is shown in (g-h). 
Graphical Abstract
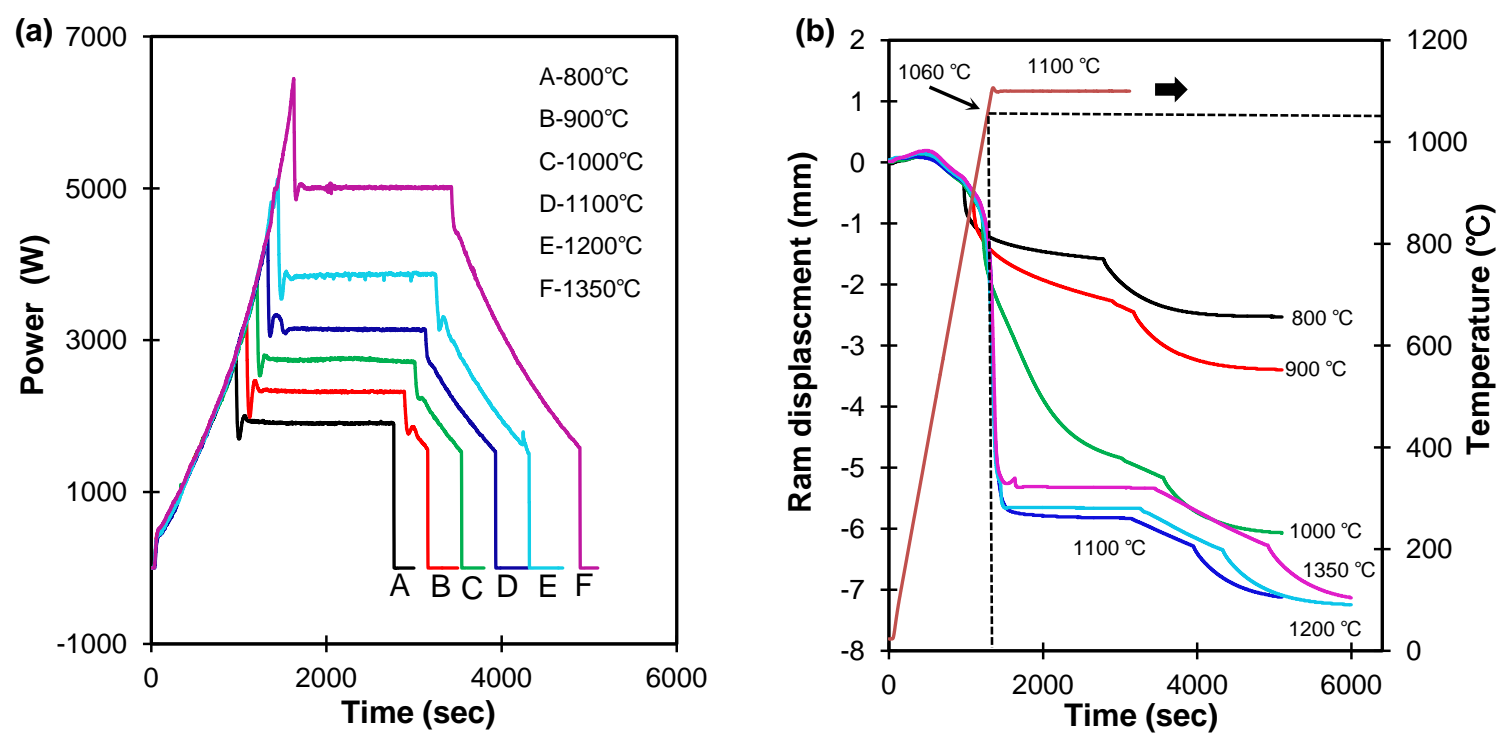